\title{
The effect of insecticide aerosols on lung function, airway responsiveness and symptoms in asthmatic subjects
}

\author{
C.M. Salome*, G.B. Marks*,\#, P. Savides*, W. Xuan*, A.J. Woolcock*
}

The effect of insecticide aerosols on lung function, airway responsiveness and symptoms in asthmatic subjects. C.M. Salome, G.B. Marks, P. Savides, W. Xuan, A.J. Woolcock. (C)ERS Journals Ltd 2000.

ABSTRACT: The object of this study was to compare the effect of standard and "low irritant" insecticide aerosols on lung function, airway hyperresponsiveness (AHR) and symptoms in asthmatic subjects.

A double blind randomized, crossover study was conducted in 25 asthmatic subjects who reported sensitivity to insecticide aerosols. All subjects were exposed for $30 \mathrm{~min}$, on separate occasions, to two standard insecticide formulations ( $A$ and $B$ ), one low irritant formulation (C) and a negative control aerosol. Spirometric function and chest, nose and eye symptoms were recorded during, and for $90 \mathrm{~min}$ after, the exposure. AHR to methacholine was measured $90 \mathrm{~min}$ after the exposure.

Compared to the negative control, the maximum fall in forced expiratory volume in one second (FEV1) was slightly greater after standard insecticides (mean differences from control $\pm 95 \%$ confidence interval: aerosol $A, 3.3 \pm 3.6 \%, p=0.08$; aerosol $B$, $5.1 \pm 4.7 \%, p=0.04$ ), AHR was significantly more severe (mean difference from control: aerosol $A, 0.35 \pm 0.29$ doubling doses, $p=0.028$; aerosol $B, 0.52 \pm 0.43$ doubling doses, $\mathrm{p}=\mathbf{0 . 0 2 8}$ ), and symptoms were more severe. The low irritant test aerosol (C) did not differ significantly from the negative control with respect to FEV1, AHR or symptoms.

It is concluded that some insecticide aerosols trigger symptoms and falls in lung function in some people with asthma. Furthermore, these aerosols may also increase airway hyperresponsiveness, although the mechanism of this effect has not been determined. The low irritant formulation did not appear to have the same effects. Eur Respir J 2000; 16: 38-43.
*Institute of Respiratory Medicine, University of Sydney, Sydney, Australia. "Dept of Respiratory Medicine, Liverpool Hospital, University of Sydney, Sydney, Australia.

Correspondence: C. Salome

Institute of Respiratory Medicine

PO Box M77

Missenden Rd PO

Camperdown NSW 2050

Australia

Fax: 61295506115

Keywords: Asthma

insecticide aerosols

Received: June 281999

Accepted after revision March 192000

Study supported by Reckitt \& Colman, Australia.
Patients with asthma commonly report exposure to aerosol insecticides as a triggering factor for asthma symptoms. Pyrethrum and synthetic pyrethroids have been used as insecticides for most of this century and their use in aerosol form is now widespread in the developed world. From as early as 1930 there have been reports of asthma attacks triggered by pyrethrum [1], and more recently there has been a report of a death due to sudden bronchospasm following inhalation of a pyrethrin shampoo [2]. However, there has been only one previous systematic study of the role of pyrethrum insecticides in asthma [3]. This study showed that insecticide aerosols can cause symptoms and changes in lung function in some asthmatic subjects. However, the sample size in this study was small, and only one subject had a clinically relevant fall in forced expiratory volume in one second (FEV1).

Because of a perceived need for special formulations for asthmatic and sensitive subjects, insecticide manufacturers have focused on developing new low irritant insecticide formulations. Claims that such formulations are particularly safe for asthmatics are widely promoted, but have received no formal objective testing in asthmatic subjects.

The present study was undertaken to determine whether insecticide aerosols have any effect on lung function, airway hyperresponsiveness or symptoms in subjects with a history of symptoms on exposure to domestic fly-sprays. Furthermore, the authors wished to determine whether a "low irritant" insecticide formulation had any adverse effects.

\section{Methods}

\section{Subjects}

Twenty-five asthmatic subjects, aged $>16$ yrs, with a previous history of sensitivity to insecticide aerosols were recruited from the Asthma Clinic at Liverpool Hospital (Sydney, Australia). All subjects had a previous diagnosis of asthma, required regular therapy, and had existing airway hyperresponsiveness to methacholine, with a provocative dose causing a 20\% fall in FEV 1 (PD20) $<4 \mu \mathrm{mol}$ and baseline FEV1 $>60 \%$ predicted normal. Subjects were excluded from the study if they had other major illnesses, were pregnant or breast feeding, or had had a serious exacerbation of their asthma, requiring an urgent doctor or hospital visit in the last 4 weeks.

The protocol for the study was approved by the Ethics Review Committee of the South Western Sydney Area Health Service (Australia).

\section{Study design}

The study was a randomized, double-blind cross-over study of the effects of insecticide aerosols on people with asthma who reported a history of symptoms on exposure to 
fly-sprays. Subjects were exposed to the insecticide aerosols on four separate days, at least 1 week apart. All subjects were exposed to three of the aerosols. These were a standard formulation, which had been shown to cause symptoms in a previous study (aerosol A) [3], a low irritant formulation (aerosol C) and a negative control aerosol. Because the older standard formulation is no longer commercially available, a fourth exposure was used to determine the effects of two other standard insecticide formulations (aerosols B1 and B2), both of which are currently commercially available. Subjects were randomly divided into two groups and exposed to one or other of the two sprays. The contents of all test aerosols are shown in table 1. The aerosols were activated to give a starting dose which approximates a real life situation, followed by a second dose comparable to the doses used in the study by Newton and BREsLin [3].

The effects of the exposure were determined by examining changes in symptoms affecting the chest, nose and eyes, as well as changes in spirometric function and airway responsiveness to methacholine. Spirometric function and symptoms were assessed at 5 and 15 min after each dose, and then at 15, 30, 60 and 90 min after leaving the exposure chamber. Airway responsiveness was measured 90 min after the end of each exposure.

\section{Aerosol exposure}

An exposure chamber was developed from a room at the Asthma Clinic at Liverpool Hospital. The room contained a desk and chair and was equipped with appropriate exhaust systems to adequately ventilate the room. Surfaces in the room were covered during the aerosol exposures. For

Table 1. - Contents of insecticide aerosols tested

\begin{tabular}{|c|c|c|c|c|}
\hline $\begin{array}{l}\text { Aerosol } \\
\text { sample }\end{array}$ & $\begin{array}{l}\text { Active } \\
\text { insecticide }\end{array}$ & $\begin{array}{c}\% \\
\mathrm{w} / \mathrm{w}\end{array}$ & Propellent & Base \\
\hline $\begin{array}{l}\text { Negative } \\
\text { control }\end{array}$ & - & & $\mathrm{HC}$ & Water \\
\hline $\begin{array}{l}\text { A Standard } \\
\text { insecticide- } \\
\text { older } \\
\text { formulation }\end{array}$ & $\begin{array}{l}\text { Pyrethrins } \\
\text { Tetramethrin } \\
\text { Piperonyl } \\
\text { butoxide } \\
\text { N-Octyl } \\
\text { bicycloheptene } \\
\text { dicarboxamide }\end{array}$ & $\begin{array}{l}0.30 \\
0.09 \\
\\
1.50\end{array}$ & $\mathrm{HC}$ & Solvent \\
\hline $\begin{array}{l}\text { B1 Standard } \\
\text { insecticide- } \\
\text { commercial } \\
\text { aerosol }\end{array}$ & $\begin{array}{l}\text { Allethrin } \\
\text { Tetramethrin } \\
\text { Piperonyl } \\
\text { butoxide } \\
\text { N-Octyl } \\
\text { bicycloheptene } \\
\text { dicarboxamide }\end{array}$ & $\begin{array}{l}0.27 \\
0.24 \\
\\
0.41\end{array}$ & $\mathrm{HC}$ & Solvent \\
\hline $\begin{array}{l}\text { B2 Standard } \\
\text { insecticide- } \\
\text { commercial } \\
\text { aerosol }\end{array}$ & $\begin{array}{l}\text { Pyrethrins } \\
\text { Piperonyl } \\
\text { Butoxide }\end{array}$ & $\begin{array}{l}0.35 \\
1.61\end{array}$ & $\mathrm{HC}$ & Water \\
\hline $\begin{array}{l}\text { C Low irritant } \\
\text { aerosol }\end{array}$ & $\begin{array}{l}\text { Bioallethrin } \\
\text { Bioresmethrin }\end{array}$ & $\begin{array}{l}0.28 \\
0.05\end{array}$ & $\mathrm{HC}$ & Water \\
\hline
\end{tabular}

$\% \mathrm{w} / \mathrm{w}$ : the weight of the constituent chemical as a percentage of the weight of the insecticide formulation; HC: hydrocarbon. each of the test aerosols two dose levels were assessed. The test aerosols were activated within the exposure chamber, firstly, for $4 \mathrm{~s}$, and then, $15 \mathrm{~min}$ later, for $32 \mathrm{~s}$. Based on the volume of the chamber $\left(23 \mathrm{~m}^{3}\right)$ and the output of the aerosol devices $\left(1.7 \mathrm{~g} \cdot \mathrm{s}^{-1}\right.$, of which $0.35 \%$ is active natural pyrethrum), it is estimated that the maximum concentration of the active pyrethrum was $8.3 \mathrm{mg} \cdot \mathrm{m}^{3}$ at the time of the $32 \mathrm{~s}$ dose. The maximum exposure is comparable to that which caused symptoms in the study by NewTON and BresLin [3], but is less than half the maximum dose used in their study. The estimated exposure concentration in this study was less than one tenth the "No observable effect level" (100 $\left.\mathrm{mg} \cdot \mathrm{m}^{3}\right)$ and was close to the threshold limit value (5 $\left.\mathrm{mg} \cdot \mathrm{m}^{3}\right)$ [4-6].

\section{Spirometric function}

Spirometric function was recorded on an electronic spirometer, with the subject standing. FEV1 and forced vital capacity (FVC) were measured and the highest of two measurements, reproducible to within $5 \%$ or $100 \mathrm{~mL}$, were recorded. Per cent predicted values [7] were calculated.

\section{Airway responsiveness to methacholine}

Airway responsiveness to methacholine was measured using the method of YAN et al. [8]. Methacholine was administered to the subjects via a hand-held De Vilbiss No.45 nebulizer (De Vilbiss Co., Somerset, PA, USA) in doubling doses, ranging 0.05-12.8 $\mu \mathrm{mol}$, until the FEV1 fell by $20 \%$. Response to challenge was measured by the dose response ratio, which is calculated as per cent fall FEV1/dose $(\mu \mathrm{mol})[9,10]$. Short acting $\beta$-agonists were withheld for $6 \mathrm{~h}$ and long-acting $\beta$-agonists for $24 \mathrm{~h}$ prior to testing.

\section{Symptom scoring}

Symptoms were assessed to determine both the type and the severity of symptoms. Chest symptoms were recorded as difficulty in breathing, chest tightness and cough; nose symptoms were recorded as running, blocking and sneezing; eye symptoms were recorded as itchy eyes, sore eyes and tears. A visual analogue scale (VAS) was used to measure the severity of the symptoms. For each of these nine symptoms, subjects were shown a $10 \mathrm{~cm}$ line, marked at one end "none" and at the other "the worst I can imagine" and asked to mark the point on the line which corresponded to the severity of the sensation they were experiencing at that moment. The length of the line, from zero ("none") to the point marked was measured in millimetres and used as an indicator of severity.

\section{Data analysis}

Lung function. Changes in FEV1 and FVC during and after the exposure were calculated as per cent change from the baseline measured immediately prior to exposure. The proportion of subjects with a fall in FEV1 $>15 \%$ during the exposure were calculated, and a comparison made between the test aerosol and the positive and negative controls, using 
McNemars test for proportions. The maximum per cent change in FEV1 for each subject during each exposure was calculated and compared by analysis of variance for repeated measures. The distribution of the maximum percentage falls in FEV1 did not differ significantly from the normal distribution, using the Kolmogorov-Smirnov statistic, following any of the exposures. Summary data for FEV1 are shown as means and 95\% confidence intervals throughout this article.

Airway responsiveness. Values for dose response ratio (DRR) were log-transformed prior to statistical analysis and geometric mean DRR values on the four exposure days were calculated. The DRR values were compared by analysis of variance for repeated measures. The DRR values were adjusted for nonspecific responses to the negative control and a comparison made between the test aerosol, the positive control and the commercial insecticide aerosols. DRR values are reported as geometric means, and $95 \%$ confidence intervals. Changes in DRR are reported in terms of doubling dose difference with their $95 \%$ confidence intervals.

Symptoms. Scores for chest, nose and eye symptoms were calculated for each subject at each time point as the sum of the VAS scores recorded at each time point for the three chest symptoms, the three nose symptoms and the three eye symptoms. The maximum symptom score for each subject following each exposure was determined and the maximum change in symptom score was calculated by subtracting the score at baseline from the maximum score. The maximum changes in symptom scores after each exposure were compared by analysis of variance. In addition, to examine the time course of the changes in symptoms, mean symptom scores were calculated at each time point following each exposure. Symptom scores are reported as mean VAS scores and $95 \%$ confidence intervals.

\section{Results}

Symptom data were obtained from 25 asthma subjects with mean age $38 \pm 6$ yrs. Lung function and bronchial challenge data from one subject were excluded because the subject was unable to perform reproducible expiratory manoeuvres. In the remaining 24 subjects baseline FEV1 was $80.8 \pm 5.4 \%$ pred and baseline FVC was $80.0 \pm 5.4 \%$ pred. All subjects had taken inhaled medication on most days in the month prior to the study, and 20 were taking regular inhaled corticosteroids. Two subjects were taking oral corticosteroids. On the basis of their airway hyperresponsiveness to methacholine, nine were classified as having severe or moderate airway hyperresponsiveness (AHR) and the remainder had mild AHR.

Thirteen subjects were exposed to aerosol B1 and 12 subjects to aerosol B2. The mean maximum fall in FEV1 was $9.7 \pm 5.0 \%$ after $\mathrm{B} 1$ and $9.2 \pm 7.0 \%$ after $\mathrm{B} 2$, and the mean increase in AHR from the negative control was 0.56 $(-0.02-1.1)$ doubling doses after B1 and $0.47(-0.26-1.2)$ doubling doses after B2. There were no significant differences between the effects of B1 and B2 aerosols on lung function, airway responsiveness and symptoms. Consequently, the data were combined and all subsequent analyses were performed on the combined data, and are shown below as aerosol $\mathrm{B}$.

\section{Lung function}

Exposure to the insecticide aerosols had significant effects on lung function, and these effects differed significantly between the aerosols. Figure 1 shows the time course of mean falls in FEV1, with their 95\% confidence intervals, for each of the four exposures. The fall in FEV1 was greatest at $20 \mathrm{~min}$, five min after the $32 \mathrm{~s}$ activation, but it had returned to pre-exposure levels by the end of the observation period.

The maximum fall in FEV1 differed significantly between exposures $(p=0.019)$ (table 2). Compared to the negative control the maximum fall in FEV1 was slightly greater after standard aerosol $\mathrm{A}$, with a mean difference from negative control of $3.3 \pm 3.6 \%$ fall $(p=0.08)$ and significantly greater after aerosol $\mathrm{B}$, with mean difference of $5.1 \pm 4.7 \%$ fall $(\mathrm{p}=0.04)$. The maximum fall caused by aerosol $\mathrm{C}$, the low irritant formulation, did not differ from the negative control, with a mean difference $1.3 \pm 3.2 \%$ fall $(p=0.44)$. The fall in FEV1 caused by aerosol $\mathrm{C}$ was significantly lower than the response to aerosol $\mathrm{B}(\mathrm{p}=$ 0.039 ), and slightly lower than the response to aerosol A $(p=0.078)$. The magnitude of the changes in FEV1 after the standard aerosols was not related to the baseline severity of AHR, measured after the negative control aerosol (for aerosol A, r=0.026 and for aerosol B, r=-0.01).

The proportion of subjects with clinically relevant falls in FEV1 (falls $\geq 15 \%$ ) after each of the aerosols is shown in table 2. The proportion was significantly greater after aerosol $B$ than after the negative control $(p=0.016)$, and was slightly greater after aerosol A than after the negative control $(p=0.06)$. After the low irritant formulation the proportion of subjects with clinically relevant falls in FEV1 did not differ from the negative control $(\mathrm{p}=0.50)$.

\section{Airway responsiveness}

Airway responsiveness to methacholine was increased by exposure to the standard aerosols (table 2). Compared to the negative control, mean dose response ratio was significantly higher (more severe) after aerosol $A(p=$ $0.028)$ and aerosol $B(p=0.028)$, but not after the low

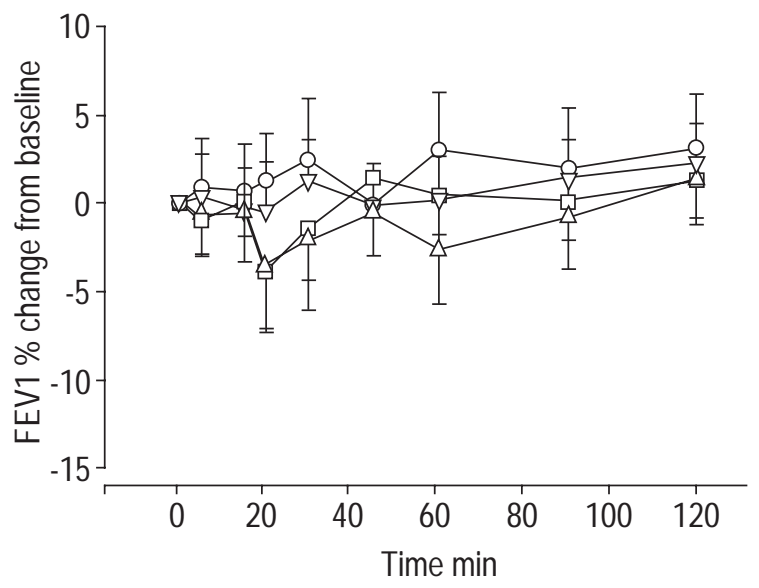

Fig. 1. - Forced expiratory volume in one second (FEV1), as per cent change from the pre-exposure value, during and after exposure to the insecticide aerosols. Values are mean and $95 \%$ confidence intervals. $\bigcirc$ : negative control; $\square$ : standard (A); $\triangle$ : standard (B); $\nabla$ : low irritant (C). 
Table 2. - Mean $\pm 95 \%$ confidence interval values for baseline lung function, and the maximum changes in lung function and symptom scores after each exposure

\begin{tabular}{|c|c|c|c|c|c|}
\hline & Negative control & Standard aerosol (A) & Standard aerosol (B) & Low irritant aerosol (C) & p-value \\
\hline Baseline FEV1 L & $2.44 \pm 0.30$ & $2.43 \pm 0.28$ & $2.43 \pm 0.30$ & $2.42 \pm 0.29$ & \\
\hline Max fall FEV1 \% & $3.9 \pm 2.6$ & $7.2 \pm 2.8$ & $9.5 \pm 4.1$ & $5.1 \pm 2.1$ & 0.019 \\
\hline $\begin{array}{l}\text { No. (\%) of subjects } \\
\text { with fall in FEV1 } \geq 15 \%\end{array}$ & 0 & $5(21 \%)$ & $7(29 \%)$ & $2(8 \%)$ & \\
\hline $\begin{array}{l}\text { Dose response ratio } \\
\text { (methacholine)* }\end{array}$ & $21.8(11.6-40.9)$ & $27.7(15.2-50.5)$ & $31.1(16.3-59.3)$ & $20.5(11.1-38.0)$ & 0.005 \\
\hline Chest symptoms & $15.2 \pm 9.2$ & $29.1 \pm 20.4$ & $36.5 \pm 21.8$ & $18.6 \pm 8.1$ & 0.119 \\
\hline Chest tightness & $5.7 \pm 3.4$ & $9.9 \pm 5.4$ & $12.1 \pm 6.1$ & $7.5 \pm 3.4$ & \\
\hline Difficulty breathing & $5.9 \pm 3.4$ & $12.1 \pm 7.0$ & $13.9 \pm 8.4$ & $7.0 \pm 2.6$ & \\
\hline Cough & $6.6 \pm 4.5$ & $13.2 \pm 8.0$ & $12.4 \pm 8.8$ & $6.5 \pm 3.3$ & \\
\hline Nose symptoms & $2.48 \pm 4.9$ & $23.1 \pm 15.9$ & $20.1 \pm 11.4$ & $11.4 \pm 6.6$ & 0.008 \\
\hline Runny nose & $2.4 \pm 1.6$ & $8.4 \pm 5.4$ & $14.8 \pm 6.3$ & $5.5 \pm 2.8$ & \\
\hline Blocked nose & $2.3 \pm 2.0$ & $9.5 \pm 6.9$ & $6.5 \pm 4.1$ & $4.5 \pm 3.3$ & \\
\hline Sneezing & $1.1 \pm 0.9$ & $9.9 \pm 6.2$ & $7.0 \pm 4.7$ & $3.8 \pm 2.8$ & \\
\hline Eye symptoms & $4.7 \pm 7.3$ & $26.6 \pm 17.8$ & $18.6 \pm 12.6$ & $9.1 \pm 4.6$ & 0.012 \\
\hline Itchy eyes & $3.1 \pm 3.6$ & $9.3 \pm 6.4$ & $6.8 \pm 4.8$ & $3.8 \pm 3.4$ & \\
\hline Sore eyes & $3.1 \pm 2.3$ & $10.5 \pm 6.4$ & $7.8 \pm 6.6$ & $3.2 \pm 2.0$ & \\
\hline Tears & $1.5 \pm 1.3$ & $11.0 \pm 7.2$ & $7.4 \pm 5.2$ & $3.7 \pm 2.1$ & \\
\hline
\end{tabular}

*: geometric mean dose response ratio ( $95 \%$ confidence interval) to methacholine indicates the severity of airway responsiveness 90 min after each exposure. The p-values show the significance of differences between exposures, based on analysis of variance for repeated measures. FEV1: forced expiratory volume in one second.

irritant aerosol $(\mathrm{p}=0.60)$. These differences remained significant when the responses to the active aerosols were adjusted for the response to the negative control $(\mathrm{p}=$ 0.0083 ) (fig. 2). The mean increase in responsiveness compared to the negative control was $0.35 \pm 0.29$ doubling doses for aerosol A and $0.52 \pm 0.43$ doubling doses for aerosol B.

\section{Symptoms}

Exposure to the insecticide aerosols caused increases in chest, nose and eye symptoms. The maximum effect occurred 5 min after the $32 \mathrm{~s}$ activation of each aerosol, but had returned to baseline levels by the end of the observation period. Figure 3 shows the time course of changes in the VAS scores for chest symptoms, nose symptoms and

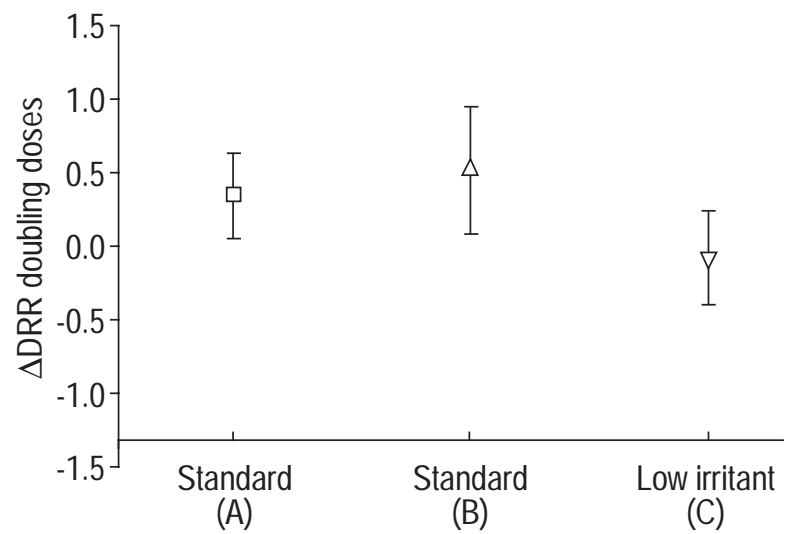

Fig. 2. - Changes in airway hyperresponsiveness (AHR) to methacholine, expressed as the doubling dose difference between dose response ratio (DRR) measured after the negative control and that after each of the active insecticide aerosols. A positive value indicates increasing severity of AHR. Values are mean and $95 \%$ confidence intervalues. $\Delta$ : change. eye symptoms. The mean change in maximum VAS scores for chest symptoms, nose symptoms and eye symptoms are shown in table 2. Symptom scores tended to be highest after aerosol $\mathrm{B}$ and aerosol $\mathrm{A}$, intermediate after aerosol $\mathrm{C}$ and lowest after the negative control. Compared to the negative control, aerosol A caused significantly more severe nose and eye symptoms, aerosol B caused significantly more severe chest and nose symptoms. Following aerosol B the magnitude of the maximum fall in FEV1 was significantly correlated with the maximum score for chest symptoms $(r=0.43, p=0.02)$, but not with nose or eye symptoms. The low irritant aerosol did not differ significantly from the negative control for any set of symptoms as assessed by the multi-range hypothesis test.

\section{Discussion}

The authors have reported the results of a randomized, double-blind crossover study of the effects of insecticide aerosols on people with asthma who report a history of symptoms on exposure to fly-sprays. The study compared the effects of three standard insecticide formulations, one of which had previously been shown to cause symptoms [3], with those of a negative control. In addition the effects of a low irritant formulation were examined. The study has shown that the standard insecticide formulations caused significant adverse effects on lung function, AHR and symptoms. In contrast, the low irritant formulation appeared to have no significant adverse effects.

The subjects selected for this study had asthma ranging in severity from mild through to severe, but all reported having previously experienced chest, nose or eye symptoms following exposure to domestic fly-sprays. There was no association between the severity of asthma and the severity of the response to the insecticide aerosols in this study, suggesting that any risk associated with exposure to fly-sprays is not confined to subjects with severe asthma. The prevalence of sensitivity to insecticide aerosols among 


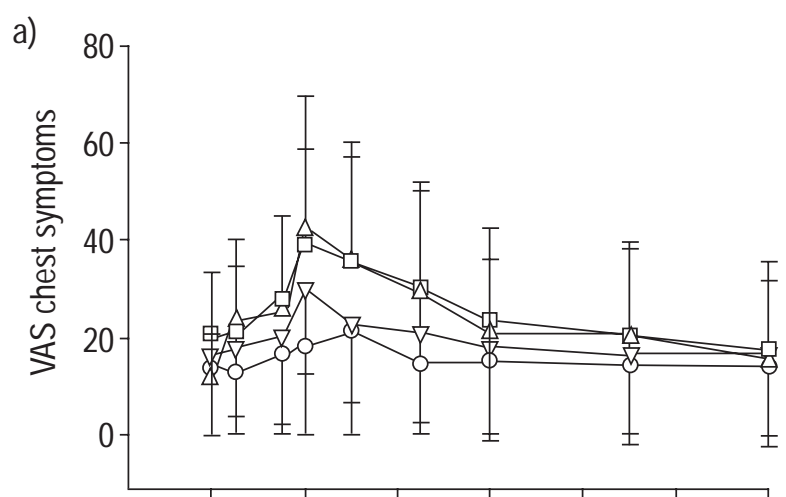

b)
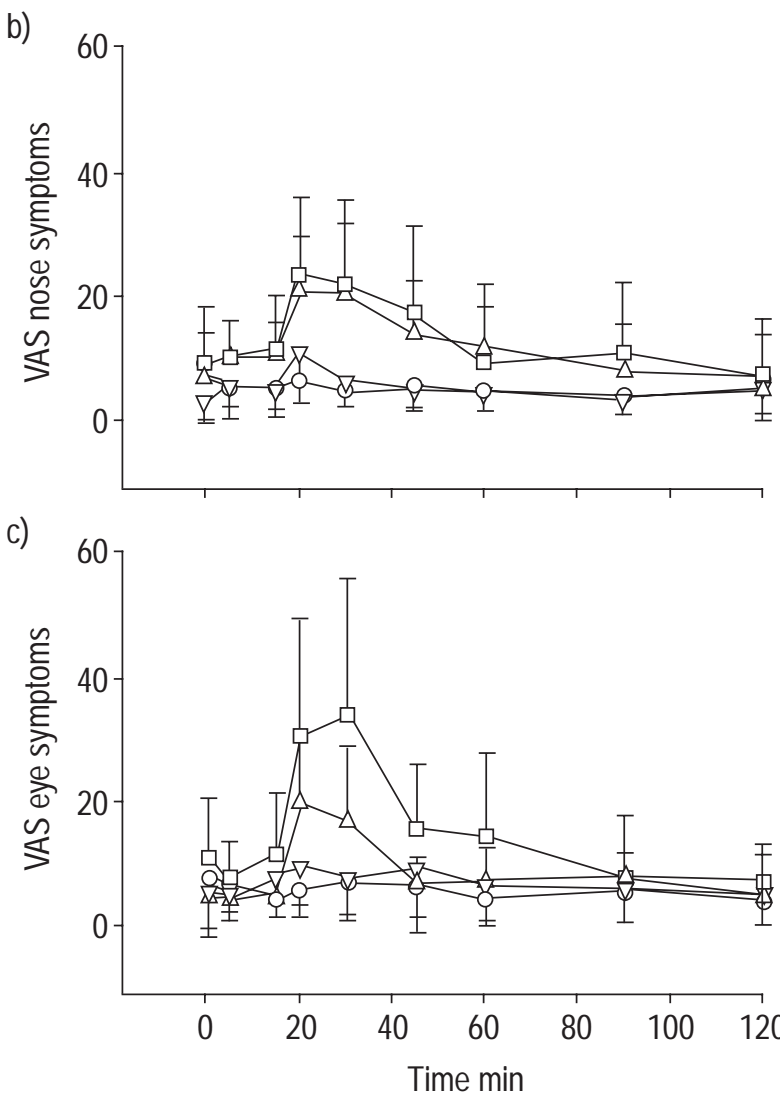

Fig. 3. - Mean scores for chest (a), nose (b) and eye (c) symptoms, as the summation of visual analogue scale (VAS) scores for difficulty breathing, wheeze and chest tightness (chest symptoms), blocking, running and sneezing (nose symptoms) and itching, sore eyes and tears (eye symptoms), during and after exposure to the negative control aerosol $(\bigcirc)$, standard aerosol A $(\square)$, standard aerosol B $(\triangle)$ and the low irritant aerosol $(\nabla)$. Values are mean and $95 \%$ confidence intervals.

asthmatic patients is not known, but clinical experience suggests that it may be common. In a community population sample, $22.7 \%$ of respondents reported chemical intolerance, defined as feeling ill on exposure to at least three of a panel of five common chemicals (paint, pesticides, car exhaust, new carpet and perfume) [11]. Among these subjects, asthma and respiratory symptoms, including wheeze, and chest tightness were common. For this study, subjects with a history of symptoms associated with insecticide use were selected because they were likely to be the subjects most at risk from an adverse effect of insecticide aerosols, and most likely to be targeted by marketing strategies aimed at insecticide sensitive asthmatics.

This analysis has confirmed that the older standard insecticide formulation, used in a previous study [3], caused adverse effects on lung function and symptoms. The other two standard formulations, which are still commercially available in Australia, had similar, but more severe, adverse effects. The magnitude of the mean change in both lung function and symptoms was small. However, seven $(29 \%)$ of the subjects exposed to the commercially avail-able aerosols experienced clinically relevant falls in FEV1, suggesting there is potential for a significant clinical problem at high levels of exposure. Unlike the study of NEWTON and BRESLIN [3], the present study has shown that exposure to these standard insecticide aerosols was associated with more severe airway responsiveness than was measured after the negative control aerosol. This difference in findings may be due to the fact that in the previous study only four subjects had AHR measured before and after exposure, and the measurement of AHR was made $24 \mathrm{~h}$ after the insecticide exposure. In the present study, the effect on AHR was small, approximately half a doubling dose, and was measurable $90 \mathrm{~min}$ after completion of the exposure.

The mechanism by which insecticide aerosols affect the airways is unclear. The effect is unlikely to be due to the toxicity of the active ingredients. The dose of insecticide was below the established "No observable effect" level and close to the threshold limit value [4-6]. In insects, pyrethroids kill by a direct effect on the nervous system, but this is avoided in mammals by rapid hydrolysis in the liver [12]. Numerous studies have shown that domestic irritants such as perfumes [13,14] or hairsprays [15] can cause a change in lung function. None of these studies have examined the effect on AHR, so it is not clear whether these substances can affect AHR directly, and the cause of the change in AHR in the present study remains unclear. Although the insecticide aerosols caused a fall in lung function immediately after the exposure, by the time the challenge test was performed, FEV1 had returned to baseline levels. It is possible that other parameters of lung function remained abnormal at this time, but it seems unlikely that the change in AHR could be explained on airway geometry alone. Pyrethrum is obtained from an extract of the chrysanthemum flower, and has been associated with allergic rhinitis and contact dermatitis $[12,16,17]$. Insecticide aerosols contain purified pyrethrins or synthetic pyrethroids, which are structurally similar to the natural pyrethrin molecule. Despite reports of "allergic" responses to synthetic pyrethroids [12], including a fatality due to sudden bronchospasm [2], no data have been reported to suggest that these responses are due to an immunoglobulin E-mediated allergic response. At present there are insufficient data either from previous studies or the present study to determine the mechanism of the adverse effects of insecticide aerosols on the airways.

The low irritant formulation did not cause significant adverse effects on lung function or symptoms. Furthermore, the data from this sample suggest that, if there is any fall in FEV1 attributable to this test aerosol, it averages $<4 \%$ in this susceptible population and is not likely to be clinically significant. Comparison of the low irritant formulation with the other sprays shows that it causes a lesser 
reduction in lung function than the two commercially-available sprays and less eye symptoms than the older formulation. Other differences between the low irritant formulation and both the older formulation and the commercially-available sprays tended to favour the low irritant formulation but did not reach statistical significance. The active insecticides in the low irritant formulation differed in chemical structure from those in the standard aerosols, but it was beyond the scope of the present study to identify the relevant chemical differences responsible for the different effects.

In conclusion, this study provides objective evidence that subjects who report chest, nose, or eye symptoms following exposure to domestic fly-sprays may be at risk of significant changes in lung function, and an increase in airway responsiveness. The exposure levels used in this study are higher than those which occur with normal domestic use of insecticide aerosols, but could be achieved by over-zealous use in a confined space. Further studies may help to determine whether the mechanism of action is due to an irritant effect of the spray on sensory nerves in the airways, or whether there is any evidence of an immunoglobulin E mediated allergic response. These findings support the view that the low irritant formulation is unlikely to cause clinically significant adverse effects in patients with asthma and that, in this respect, it represents an improvement on the standard formulations.

\section{References}

1. Ramiraz MA. Pyrethrum: an aetiologic factor in vasomotor rhinitis and asthma. Allergy 1930; 1: 149-155.

2. Wax PM, Hoffman RS. Fatality associated with inhalation of a pyrethrin shampoo. J Toxicol Clin Toxicol 1994; 32: 457-460.

3. Newton JG, Breslin ABX. Asthmatic reactions to a commonly used aerosol insect killer. Med J Aust 1983; 1: 378-380.

4. Tomlin C, ed. The pesticide manual. 10th ed. The Royal Society of Chemistry \& the British Crop Protection Council, 1994.
5. Miyamoto J. Degradation, metabolism and toxicity of synthetic pyrethroids. Env Health Perspectives 1976; 14 : 15-28.

6. Casida JE, Quistad GB, eds. Pyrethrum Flowers. Production, chemistry, toxicology and uses. Oxford, UK, Oxford University Press, 1995.

7. Morris J, Koski A, Johnson L. Spirometric standards for healthy non-smoking adults. Am Rev Respir Dis 1971; 103: 57-67.

8. Yan K, Salome C, Woolcock A. Rapid method for the measurement of bronchial responsiveness. Thorax 1983; 38: 760-765.

9. Peat JK, Salome CM, Berry G, Woolcock AJ. Relation of dose-response slope to respiratory symptoms and lung function in a population study of adults living in Busselton, Western Australia. Am Rev Respir Dis 1992; 146 : 860-865.

10. O'Connor G, Sparrow D, Taylor D, Segal M, Weiss S. Analysis of dose response curves to methacholine. An approach suitable for population studies. Am Rev Respir Dis 1987; 136: 1412-1417.

11. Baldwin CM, Bell IR, O'Rourke MK, Lebowitz MD. The association of respiratory problems in a community sample with self-reported chemical intolerance. Eur $J$ Epidemiol 1997; 13: 547-552.

12. O'Malley M. Clinical evaluation of pesticide exposure and poisonings. Lancet 1997; 349: 1161-1666.

13. Kumar P, Caradonna-Graham VM, Gupta S, Cai X, Rao $\mathrm{PN}$, Thompson J. Inhalation challenge effects of perfume scent strips in patients with asthma. Ann Allergy Asthma Immunol 1995; 75: 429-433.

14. Shim C, Williams MHJ. Effect of odors in asthma. Am J Med 1986; 80: 18-22.

15. Schlueter DP, Soto RJ, Baretta ED, Herrmann AA, Ostrander LE, Stewart RD. Airway response to hairspray in normal subjects and subjects with hyperreactive airways. Chest 1979; 75: 544-548.

16. Feinberg SM. Pyrethrum sensitisation: its importance and relation to pollen allergy. JAMA 1934; 102: 1557-1558.

17. McCord CP. Pyrethrum dermatitis: a record of occupational dermatoses among workers in the pyrethrum industry. JAMA 1921; 77: 448-449. 